\title{
Research on Application of Assembly Building Informatization Based on BIM Technology
}

\author{
Xiao Chen \\ Chengdu Normal University, Chengdu, Sichuan, 611130, China
}

Keywords: BIM technology, Assembly building informatization, Application.

\begin{abstract}
As science and technology continuously develop, the social construction in China has also been greatly accelerated in recent years. The report of the 18th National Congress of the CPC also proposed the policy line to "adhere to the new industrialization, informationization, urbanization and agricultural modernization roads with Chinese characteristics, and promote the in-depth integration of informatization and industrialization”, based on which China's construction industry is developing at an increasing speed. At the same time, due to the addition of various new technologies, the construction industry has gradually transformed from a traditional model to a new model. In this process, the requirements for construction technology have also increased. By analyzing the advantages and related requirements of fabricated buildings and combining the relevant advantages of BIM technology, this paper discusses the important role played by BIM technology in the process of assembly-type building informatization. It is hoped that BIM can be applied to the assembly building informatization, providing a reference in the process of technology.
\end{abstract}

\section{Introduction}

With the continuous advancement of our society, the concepts of energy conservation, environmental protection and sustainable development have also received more and more attention. On this basis, more and more prefabricated buildings have been recognized by people, compared with traditional architecture. As for the cost-saving and shortening of the construction period, the prefabricated building has great advantages. The prefabricated building also has the characteristics of low noise and less pollution, so that the prefabricated building greatly develops, and the development and application of BIM technology has provided strong support for the development of fabricated buildings. By using BIM technology, all aspects of the construction of the prefabricated building from design to construction can be better completed. With the continuous development of information technology, BIM as a basis for the informatization management of fabricated buildings, China's assembly-oriented building informatization management field has also made great progress. The continuous integration of the two, it not only achieves the goal of convenient and fast information management, but also integrates the professional and precise characteristics of BIM technology, which makes the information of the entire assembly building construction process more interactive.

\section{Advantages of Prefabricated Buildings}

\subsection{Significantly shorten the construction period}

As the name implies, a prefabricated building refers to a new architectural model in which the production company directly transports the building components that are scheduled to be produced to the project site and then assembles them through various machines. The origins of prefabricated buildings date back to the early 20th century, but the prefabricated buildings at that time did not receive much attention. Until the 1960s, prefabricated buildings were realized. In this mode, it is first possible to rely on machinery to replace the original manpower in many aspects, and also because it uses the building components produced by the manufacturer according to the requirements. The 
combination of these two conditions makes the construction period of the prefabricated building far lower. In the construction cycle of traditional buildings, and avoiding a lot of manpower and cost waste, it also saves construction costs to a large extent.

\subsection{Reduce resource waste and environmental pollution}

As an era of pollution and energy issues, countries around the world are vigorously advocating energy conservation and environmental protection. The appearance of fabricated buildings is very good to meet the requirements of the country. A large part of the materials used in prefabricated buildings can be recycled, such as related templates, which can achieve a good reduction. The goal of resource loss, at the same time, because it only needs to be assembled at the engineering site, it also reduces construction noise, and can also reduce dust and other factors caused by construction work, and better protect people's living environment.

\subsection{Guarantee project quality and reduce safety hazards}

In the past construction process of construction projects, due to technical limitations, there will be many situations where construction workers must work at heights. This is a certain safety hazard. It is not only the personal safety of construction workers, but also due to the high altitude work. Stability, such construction may also cause some problems in the quality of the entire construction project, so the overall safety is a concern of traditional construction. Relatively speaking, the prefabricated building greatly reduces the impact in this aspect of the construction process. The building components manufactured by the manufacturer in accordance with the requirements during the production process are more used after the transportation arrives at the construction site. The construction machinery is completed, so in the case of ensuring safety, the quality of the entire building can be better protected, thereby minimizing safety hazards.

\subsection{Cost and labor savings}

Also, since the building components of the prefabricated building are ordered in batches at the production enterprise, they can be completed by directly transporting them to the construction site for assembly, making it important for traditional construction throughout the production and construction process. The use of scaffolding and stencil molds is much reduced, which saves construction costs and reduces some construction processes, resulting in a significant savings in labor.

\subsection{Unaffected by climate and weather}

In the process of traditional building construction, there are many processes that are more demanding on factors such as climate. If the climate or weather is not suitable, there will be no way for the construction project to go smoothly. In severe cases, it may even stop working. Extending the engineering cycle to a large extent also increases unnecessary cost loss. Relatively speaking, the prefabricated building is much simpler. Since the building components are produced at the factory after being accepted by the corresponding manufacturer, it is usually hardly affected by the weather and the weather. The transportation of these components to the construction site for installation can be largely rid of the idea of "engineering to start work".

\section{Advantages of BIM's Fabricated Building Informatization Application}

\subsection{Visualization of BIM technology}

As a new technology, the most obvious advantage of BIM technology lies in its visibility, which can be displayed in a form that can be seen intuitively. Compared with traditional architectural projects, it is necessary to use the drawings to carry out the spatial imagination mode. Vision can undoubtedly display the actual situation of the building more intuitively, thus providing a very clear reference material for the engineering links including design and construction, which guarantees the quality of the overall project. 


\subsection{Coordination of BIM technology}

Whether it is traditional construction engineering or new construction engineering, it is very important to have good coordination between various units. When applying BIM technology, it is convenient to provide the coordination and cooperation between units. Provide accurate data from all levels of construction, help the various departments of the entire project to better coordinate and solve communication problems.

\subsection{Analogity of BIM technology}

After the completion of the construction project, how the actual situation is a problem that has been plaguing traditional construction projects. Problems like thermal insulation, lighting and ventilation can only be speculated by experience in traditional buildings, but it can be solved well by applying BIM technology. This kind of problem, by applying the simulation characteristics of BIM technology, can directly simulate the situation after the completion of the construction project to confirm the actual situation. At the same time, it is also possible to simulate the corresponding situation of the building as time changes, which makes it easier for the construction unit and the project unit to correctly understand the overall situation and future situation of the construction project, and is more conducive to the construction efficiency and quality improvement of the entire construction project.

\subsection{BIM technology optimization}

Similarly, based on the simulation of BIM technology, it can also optimize the deficiencies of the project while constructing the construction project, and make more reasonable adjustment and optimization of the whole project by understanding the future changes of the project. It can both effectively reduce the secondary construction and provide great convenience for the later maintenance after the end of the construction project.

\subsection{Graphicality of BIM technology}

The plotting characteristics mentioned here do not refer to the plan and structure drawings used in traditional building construction, but on the basis of the visibility of BIM technology, and more intuitively understand the internal conditions of the building, thus building engineering. The reserved structures of pipelines, openings, etc. provide clear drawings, formulate construction plans or improve construction plans according to the drawings, thereby largely avoiding errors and reducing waste of unnecessary manpower and resources.

\section{The Application of BIM Informatization Technology}

\subsection{Application of BIM technology in design}

The design process is very important for the construction of the building, and it is no exception for the assembled building. Due to the particularity of the assembly building, the building components not only need to meet the safety and functional problems, but also need to consider the subsequent assembly problems. In this aspect, the BIM technology can be used to fully understand the assembly type through the model construction. The requirements of all aspects of the structure during the construction process can also provide very important reference data for the selection of different components in the design process, which can improve the efficiency of the overall design modeling. At the same time, the combination of BIM technology and digital collaborative design technology can automatically correlate the information related to the design, production and assembly of the design model by correlating the simulation data of each stage of the building model and the assembly construction process. Integration, fully meet the data association and sharing of the later manufacturers and even the engineering site assembly. When the production enterprises are producing, they can also obtain more clear indicators through the relevant data obtained by BIM technology, so as to more accurately produce the building components. Effectively avoid the problem 
of information asymmetry in the sound field process.

\subsection{Application of BIM technology in factory production}

As a unique part of the prefabricated building, the production process of the factory can be said to be the most critical part of the entire assembly-type construction process. During the production process of the factory, the building components originally existing at the design level will be completed from the data to the actual In order to better meet the needs of production, it is necessary to make full use of information management technology to plan production. To maximize the interference of some human factors, and strictly follow the types of building components in BIM design. Related indicators to produce, in this case, in order to speed up production and reduce the loss of human resources, you can also improve the accuracy degree of the entire production process by importing BIM design data into the central control system of information control, to achieve lean production. On this basis, the production enterprise information management system can finally achieve an information management of the whole process of producing materials to components into and out of the warehouse by combining with the technology of the object.

\subsection{Application of BIM technology in field assembly}

On-site assembly refers to the process of actually assembling the building components produced by the manufacturer to the construction site. This process is mainly based on the BIM model, and refers to the building engineering design information and the building components of the production enterprise. Information, in order to achieve the BIM model in the assembly process, fully realize the assembly process, the entire project's progress and cost situation into accurate data, making management more intuitive and convenient. At the same time, due to the informatization of all aspects of construction, it is also possible to better avoid some follow-up problems in construction projects and improve the overall construction efficiency and construction quality of construction projects.

\section{BIM-ERP Informatization Management Application}

\subsection{Establish an integrated information management platform based on BIM}

To establish an integrated information management platform based on BIM, it is first necessary to establish a corresponding data center at the group headquarters, and then establish a reasonable micro front-end to carry out production from BIM design to production enterprise through the actual situation in the project process. The data collection work of the entire process of assembly at the construction site, through the data center analysis, micro-front-end collection mode to gradually form the company's own unique database, thus achieving the purpose of collaborative office.

\subsection{Information management of EPC engineering construction}

To form a corresponding information management for EPC projects, first of all, it is necessary to pay attention to the relevant information of the model formed under BIM technology, and at the same time, support the model information and construction engineering related information as the basis, so as to achieve the assembly construction process. The relevant information between the processes can better communicate with each other, thus ensuring the smooth construction of the construction project. On this basis, through the improvement of the BIM integrated information management platform, the integrated management of EPC engineering construction will continue Perfected, it will eventually reach the whole process from the design of the prefabricated building to the end of the whole project, such as production, procurement, etc., which can be managed in an informational way and provide important reference for the more effective use of the Group's assets. 


\section{Summary}

In order to better respond to the sustainable development concept and environmental protection concept advocated in China, the prefabricated building has ushered in a very large development opportunity. At the same time, the integration of BIM technology and informatization management concept also provides a new development route for a prefabricated building. The integrated information management platform and EPC engineering information management generated by the integration of BIM technology and information management concept not only realize the goal of convenient and fast information management, but also integrate the professional and precise characteristics of BIM technology, making the information on the whole prefabricated building construction process more interactive. The precise characteristics make the information of the entire assembly building construction process more interactive. Through continuous improvement and innovation, it is believed that the assembled building information management model using BIM technology will inevitably promote the development and progress of the entire assembly-type construction industry, and will eventually play a significant role in the development of the construction industry and the social construction in China.

\section{References}

[1] Yu Longfei, Zhang Jiachun. Integrated Building Construction System Based on BIM, Journal of Civil Engineering and Management, 2015, 04: 73-78+89.

[2] Li Yong, Guan Changsheng. Information Management Model and Strategy of Engineering Project Based on BIM Technology, Journal of Engineering Management, 2012, 04: 17-21.

[3] Bai Wei, Zhang Yankun, et al. Analysis of the Application Value of BIM Technology in Prefabricated Buildings, Construction Economy, 2015 (11): 106-109. 